\title{
Mechanical Characterization of PU Based Sandwich Composites with Variation in Core Density
}

\author{
Sunith Babu L., " , H. K. Shivanand ${ }^{2}$ \\ ${ }^{1}$ Dept of Mechanical Engineering, MSRIT, Bangalore, India \\ ${ }^{2}$ Dept of Mechanical Engineering, UVCE, Bangalore, India
}

Email address:

sunithbabu@msrit.edu (Sunith Babu L.)

\section{To cite this article:}

Sunith Babu L., H. K. Shivanand. Mechanical Characterization of PU Based Sandwich Composites with Variation in Core Density. International Journal of Materials Science and Applications. Vol. 4, No. 4, 2015, pp. 277-282. doi: 10.11648/j.ijmsa.20150404.19

\begin{abstract}
Sandwich composite finds its application in varied fields of engineering, mainly due to the fact that they are light weight, have a better strength to weight ratio and to an extent corrosion resistant. Each application might involve different fabrication technique and selection of appropriate foam core and facings. In this study, three different core densities of PU foam combined with glass fiber facings are fabricated using vacuum bagging technique. Because of their complex nature of fabrication by adding epoxy resin between facings and core makes the evaluation of their mechanical characteristics quite difficult to predict. Since core material being the weakest part of the sandwich composite, studies are carried out to determine the effect of change in mechanical properties by increasing the core thickness and density. Further, the mechanical response of these sandwich composites are studied by carrying out flatwise, edgewise compressive test and flexural strength on a Mecmesin MultiTest 10-i testing equipment as per ASTM standards. It is found that with increase in core density the flatwise compressive modulus increases and facesheet wrinkling in low density foam and core debonding in higher density foam was noticed in edgewise compression. The flexural tests showed that with increase in core thickness marginally increased the face being stress as compared with increase in core density.
\end{abstract}

Keywords: Flatwise Compression, Edgewise Compression, Polyurathene Foam Core, Vacuum Bagging Technique, Sandwich Composite

\section{Introduction}

The sandwich composite is a structure made of three different layers, each bonded with a resin to form an effective load carrying assembly. The sandwich structures are increasingly being used in different applications and one such area is related to aerospace. With higher strength to weight ratio, their stiffness increases to a greater extent and can be used in different parts of aircraft structure thereby making it a lightweight structure. However, the intermediate material used in sandwich composites are made of core and they tend remain as weaker section of the composites. Apart from aerospace, sandwich composites are also being used in applications related to marine and consumer application. In such situations, the performance of the sandwich composites remain important.

S.C Sharma et, al.[1] have found that the face sheet material carries tensile and compressive stresses mainly due to in planar loads. Further combination of flexural and compressive strength together results in weight savings for the composite structure. M. Mohamed [2] carried out mechanical characterization of sandwich structure based on PU foams with GFRP sandwich panels and showcased that with increase in core density, the face bending stress increases.

Dai et al. [3] determined the effect of failure studies on the sandwich beams mainly manufactured by VARTM process for a 3 - point and 4 - point flexural process using a different core materials. It was found from the tests that the sandwich beams which were long tend to fail on the tensile side of the face. However, the tensile strength tend to increase. Manalo AC et al [4] carried out flexural studies on the sandwich beam made from glass fiber facings with a phenolic based cores. The results showed that the failure happened at the edgewise compression process with a higher loads and relatively less deflection in the flatwise compression. Xiong et al. [5] carried out studies on the effect of facing compressive strength and edgewise compressive strength on a two face carbon / epoxy facings with a pyramidal truss core sandwich composite material. It was found that after the peak load the facings deboned from the core leading to decrease in load carrying capacity. 
Carlsson L et al. [6] have determined that during the testing of sandwich composites in static or cyclic conditions, the core is the major part of the sandwich which can help in controlling the failure of the sandwich composite even though they tend to weaker portion of the sandwich structure. Asad Mirzapour et al. [7] studied the effect of rigid polyurethane foam cores under flexural loading with varied curing temperatures. It was found that the debonding strength drastically increased with increase in curing temperature and flexural strength tend to remain high at an optimum temperature of $70^{\circ} \mathrm{c}$.

Vijay Kumar. Ma et al. [8] carried out flexural tests on multilayered PU foam core sandwich panels where in the thickness sandwich panel was kept constant with varying core and facing thickness \& variation in core density. The results showed that with variation in core density resulted in increase in flexural strength. Jongman $\mathrm{K}$ et al. [9] found that the failure on the sandwich structure can happen at different locations and categorized the failure between face and core interface, failure of the face due to breakage of fibers and core failure due to compression and revealed that the failure is mainly due to adhesion characteristics between face and core interface.

Sourabha S Havaldar and Ramesh S Sharma [10] carried out an investigation the dynamic characteristics of multilayered PU foam based sandwich composites, the test results showed that dynamic response of the sandwich composites can be increased by modifying the number of core layers within the sandwich structure.

Generally over the years, researchers have dealt with the effect of facings and its influence on the sandwich structure. Much of the work is still in the infancy stage with core material being considered for the performance of the sandwich structure and specific work on mechanical characterization of sandwich structure with varying core densities and constant facing thickness are little explored. Although there are several issues related to the factors influencing core $\&$ face thickness and its effect on mechanical properties, these tend to provide a good information the researches in determining the range of applications such composites can provide.

Hence in this paper investigation of change in core density and core thickness of a sandwich structure is taken up and tests related to flatwise and edgewise compressive strength are found. Further the effect of flexural strength and its influence on the core thickness and core density are evaluated and recorded.

\section{Experimental Methodology}

\subsection{Specimen Preparation}

The sandwich composites are fabricated using a vacuum bagging technique by selecting three core densities of $70 \mathrm{~kg} / \mathrm{m}^{3}$, $100 \mathrm{~kg} / \mathrm{m}^{3}$ and $200 \mathrm{~kg} / \mathrm{m}^{3}$, further the thickness of the core material selected were $10 \mathrm{~mm}$ and $14 \mathrm{~mm}$ for all the densities selected. The specimens were fabricated with facing thickness being retained at $1 \mathrm{~mm}$ using GFRP material. The facings material GFRP along with foam made of PU based material of different densities were fabricated using a vacuum layup process technique where in 4 layers of lamina each with a thickness of $0.22 \mathrm{~mm}$ were stacked together at bottom with the application of adhesives made from LY556 and HY951 in the ratio 10:1. This setup were in turn kept for curing by placing them in a vacuum condition and allowing entrapped air within the laminates and foam to be removed completely as shown in Figure 1. Later the top side of the foam was bonded with $1 \mathrm{~mm}$ GFRP facings to create a stiff sandwich panel. The experiments were carried out at a constant loading rate of $4 \mathrm{~mm} / \mathrm{min}$.

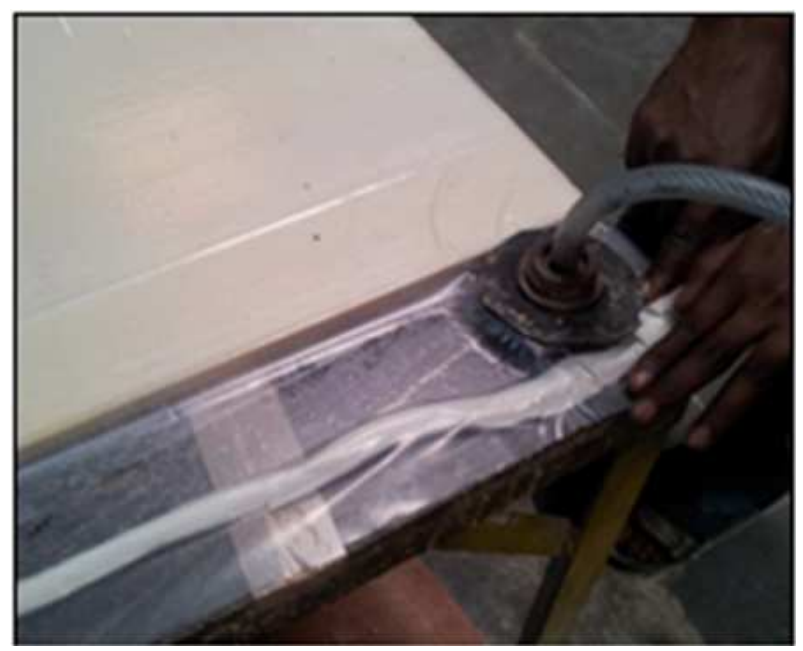

Figure 1. Sandwich panel fabricated using vacuum bagging technique.

The specimens were coded for better understanding of each type as shown in Table 1, $2 \& 3$, with core thickness $10 \mathrm{~mm} \&$ $14 \mathrm{~mm}$ and facing thickness $1 \mathrm{~mm}$

Table 1. Glass fiber sandwich specimen for flatwise compressive test.

\begin{tabular}{lll}
\hline Specimen Designation & Core Density $\left(\mathbf{k g} / \mathbf{m}^{3}\right)$ & $\mathbf{L} \times \mathbf{B}(\mathbf{m m})$ \\
\hline $\mathrm{FW}_{1}$ & 70 & $50 \times 50$ \\
$\mathrm{FW}_{2}$ & 100 & $50 \times 50$ \\
$\mathrm{FW}_{3}$ & 200 & $50 \times 50$ \\
$\mathrm{FW}_{4}$ & 70 & $50 \times 50$ \\
$\mathrm{FW}_{5}$ & 100 & $50 \times 50$ \\
$\mathrm{FW}_{6}$ & 200 & $50 \times 50$ \\
\hline
\end{tabular}

Table 2. Glass fiber sandwich specimen for edgewise compressive test.

\begin{tabular}{lll}
\hline Specimen Designation & Core Density $\left(\mathbf{k g} / \mathbf{m}^{3}\right)$ & L x B (mm) \\
\hline Ew $_{1}$ & 70 & $90 \times 50$ \\
$E_{2}$ & 100 & $90 \times 50$ \\
$E_{3}$ & 200 & $90 \times 50$ \\
$E_{4}$ & 70 & $90 \times 50$ \\
$E_{5}$ & 100 & $90 \times 50$ \\
$E_{6}$ & 200 & $90 \times 50$ \\
\hline
\end{tabular}

Table 3. Glass fiber sandwich specimen for flexural test.

\begin{tabular}{lll}
\hline Specimen Designation & Core Density $\left(\mathbf{k g} / \mathbf{m}^{\mathbf{3}}\right)$ & $\mathbf{L} \times \mathbf{B}(\mathbf{m m})$ \\
\hline $\mathrm{F}_{1}$ & 70 & $150 \times 50$ \\
$\mathrm{~F}_{2}$ & 100 & $150 \times 50$ \\
$\mathrm{~F}_{3}$ & 200 & $150 \times 50$ \\
$\mathrm{~F}_{4}$ & 70 & $150 \times 50$ \\
$\mathrm{~F}_{5}$ & 100 & $150 \times 50$ \\
$\mathrm{~F}_{6}$ & 200 & $150 \times 50$ \\
\hline
\end{tabular}




\subsection{Flatwise Compressive Testing of Sandwich Specimen}

The sandwich panels were cut based on the ASTM standards C365 - 94 with a dimension of 50x50 sides and two different thickness of $12 \& 16 \mathrm{~mm}$.

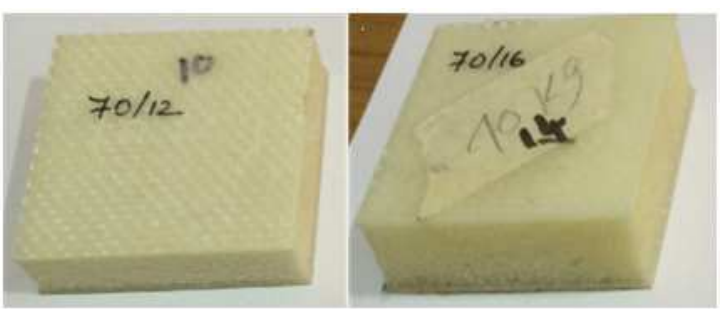

Figure 2. Flatwise compressive test specimen.

Six specimen were tested for flatwise compressive test. The test was carried using a Mecmesin - Multi Test - 10i machine. A spherical loading block was attached to the machine and the load was gradually applied at a constant loading rate of $4 \mathrm{~mm} / \mathrm{min}$. The cross sectional area was $2500 \mathrm{~mm}^{2}$, which is

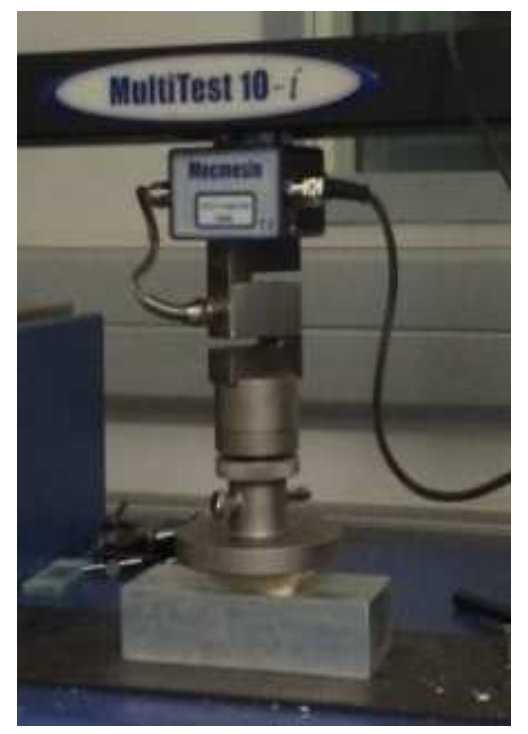

a. higher than the recommended minimum cross sectional area of $625 \mathrm{~mm}^{2}$ for foam based sandwich composites as per ASTM standards. The load - deflection graphs were obtained and plotted. The flatwise compressive strength is obtained from the ultimate load. The test condition is shown in Fig $3 \mathrm{a}$.

\subsection{Edgewise Compressive Testing of Sandwich Specimen}

The sandwich specimens were cut based on the ASTM 364 - 94 standards as shown in Fig 3b. The test specimen is prepared based on the following criteria: test specimen should be rectangular in shape, width of the specimen should be at least $50 \mathrm{~mm}$ minimum or greater and the unsupported length should not exceed eight times the total sandwich thickness

Based on the above criteria, the specimen was made with the dimensions as listed in Table 2. The total unsupported length of the sandwich specimen was maintained at $90 \mathrm{~mm}$ for both thickness of $12 \mathrm{~mm}$ and $16 \mathrm{~mm}$. The testing is carried out through a constant loading rate of $4 \mathrm{~mm} / \mathrm{min}$ the load vs deflection plots are obtained and edgewise compressive strength are obtained after the test.

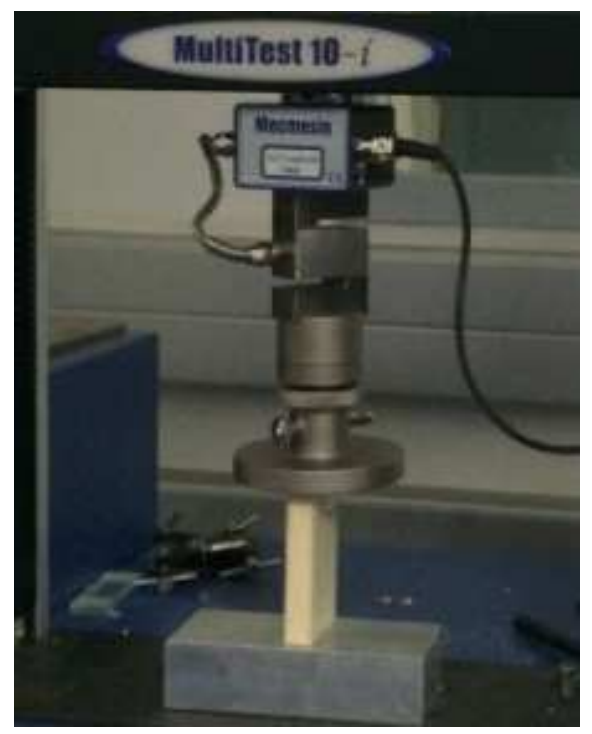

b.



c.

Figure 3. Sandwich specimen testing a. Flatwise b. Edgewise c. Flexural. 


\subsection{Flexural Testing of Sandwich Specimen}

Apart from flatwise and edgewise compressive testing, flexural testing becomes more important since this test helps in determining the core shear stress, face bending stress and sandwich beam deflection process. The three point bend tests were carried out as per ASTM C393-94 as shown in Figure 3c. The tests was carried out at room temperature with a constant load rate of $5 \mathrm{~mm} / \mathrm{min}$. The load is applied in the mid span length of $100 \mathrm{~mm}$. After the tests are conducted, the face bending stress is calculated based on equation 1 .

$$
\sigma_{2}=\mathrm{PL} /\{2 \mathrm{t}(\mathrm{d}+\mathrm{c}) \mathrm{b}
$$

\section{Results and Discussion}

\subsection{Flatwise Compressive Modulus}

The flatwise compressive tests were performed on all six

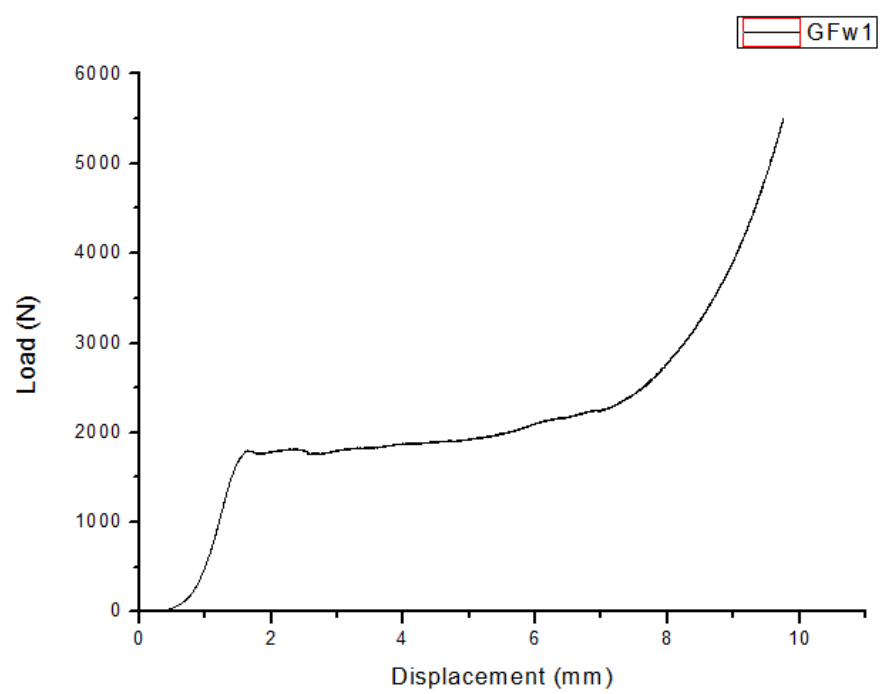

4a)

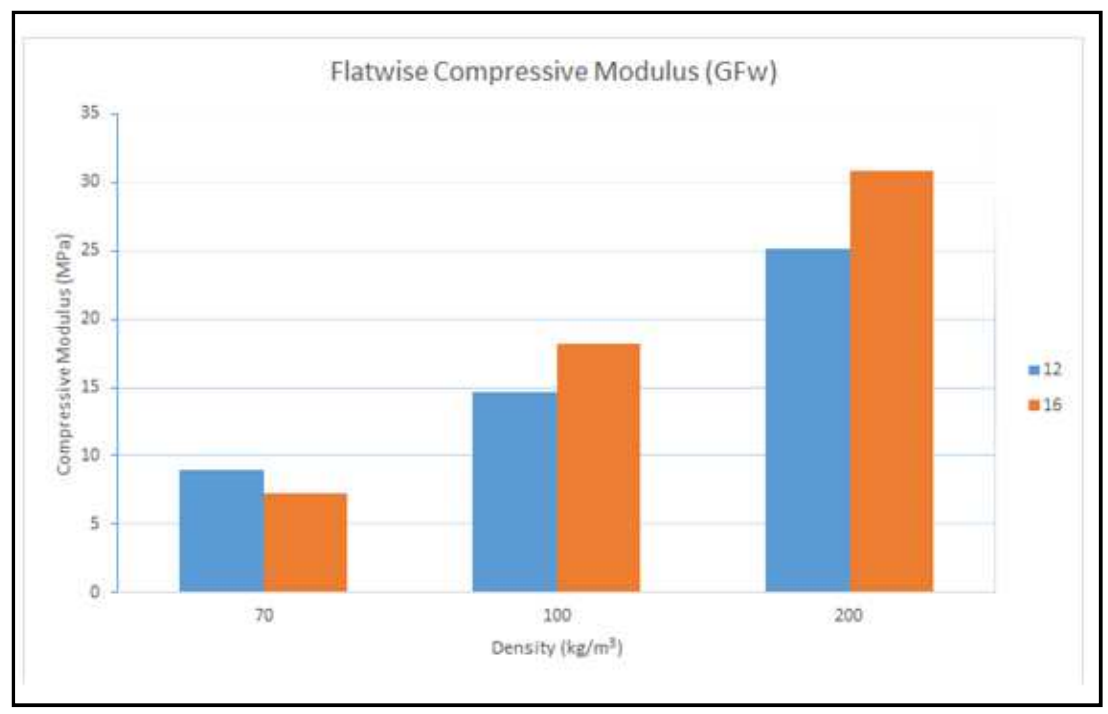

4b) specimen and it was found that as the thickness of the sandwich increased, the ultimate load on the sandwich specimen increased. Figure $4 \mathrm{a}$ shows one of the load deflection curve for the flatwise compression test for GFw1. It is found that the curve moves linear till an ultimate load is reached which is the facing compressive strength. Further, the curve drops due to the bending and local buckling of cell walls within the foam. The load further increased due to the densification of the foam cell walls. It is clear further from Fig $4 \mathrm{~b}$ that with increase in core thickness, the compressive modulus increases. The flatwise compressive modulus is obtained by using equation 2

$$
\mathrm{E}=\mathrm{St} / \mathrm{A}
$$

Here, $\mathrm{S}$ is the slope from the Load vs Deflection cure and $\mathrm{t}$ is the thickness of the core and A is the cross sectional area of the facings subjected to compression. 


\subsection{Edgewise Compressive Tests}

The edgewise compressive tests were performed on two types of sandwich specimens made of $90 \times 50 \times 12 \mathrm{~mm}$ and $90 \times 50 \times 16 \mathrm{~mm}$. In any edgewise compressive test, the failure of the sandwich beam or specimen can be of four types namely facesheet buckling (I), facesheet compression failure (II), core compression failure (III) and core shear failure (IV). From the load deflection curve, the maximum load is obtained and the facing compressive stress is obtained.

Table 4. Edgewise compression test results.

\begin{tabular}{lll}
\hline $\begin{array}{l}\text { Specimen } \\
\text { Designation }\end{array}$ & $\begin{array}{l}\text { Facing Edgewise } \\
\text { Compressive Stress (MPa) }\end{array}$ & $\begin{array}{l}\text { Mode Failure } \\
\text { Type }\end{array}$ \\
\hline Ew $_{1}$ & 0.363 & I \\
$E_{2}$ & 0.497 & II \\
$E_{3}$ & 0.612 & I, III \\
$E_{4}$ & 0.420 & III \\
$E_{5}$ & 0.732 & IV \\
$E_{6}$ & 0.850 & IV \\
\hline
\end{tabular}

It is found from table 4, with increase in core density, there is a marginal increase in ultimate load. It is found that when the core density increases from $100 \mathrm{~kg} / \mathrm{m}^{3}$ to $200 \mathrm{~kg} / \mathrm{m}^{3}$, the ultimate load does not increase by two folds. This may be due to interface debonding between the core and facings, which displayed type IV failure where in the core sheared after a load of 6594 reached as shown in Fig 5(1). The facings de bonded from the core for GEw2 \& GEw3 samples. However the displacement steadily increased as the core density increased.

\subsection{Flexural Tests}

In order to determine the static behavior of the sandwich panels, 3 point bend test was performed to according to ASTM standards as listed in C393 - 94. The displacements were recorded and the slop was determined for each specimen from the linear portion of the graph. A constant loading of $5 \mathrm{~mm} /$ min was applied on the specimen. Each test was repeated for 3 trials and the results were averaged and tabulated in table 5. It is found that the face bending stress increases with increase in core density and marginal increase with increase in thickness.

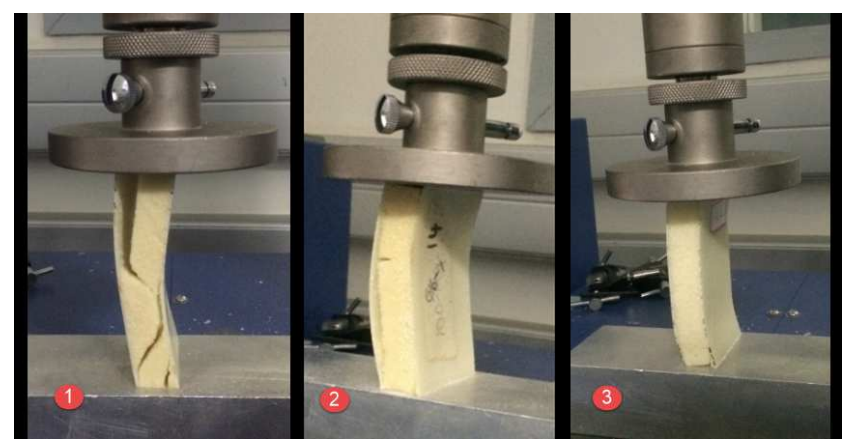

Figure 5. Edgewise compression test (1) Core shear failure (2) Face debonding (3) Core crushing.



Figure 6. Flexural testing of sandwich beam.

Table 5. Flexural test results.

\begin{tabular}{llll}
\hline $\begin{array}{l}\text { Specimen } \\
\text { Designation }\end{array}$ & $\begin{array}{l}\text { Face bending } \\
\text { stress (MPa) }\end{array}$ & $\begin{array}{l}\text { Displacement } \\
(\mathbf{m m})\end{array}$ & 3 PB(Avg) \\
\hline F1 & 38.43 & 5.517 & 2.24 \\
F2 & 52.65 & 5.15 & 2.88 \\
F3 & 89.05 & 3.18 & 2.8 \\
F4 & 30.79 & 5.669 & 2.029 \\
F5 & 42.05 & 4.35 & 2.4 \\
F6 & 80.154 & 2.69 & 2.69 \\
\hline
\end{tabular}

\section{Conclusion}

The sandwich specimen were prepared as per ASTM standards and were tested for flatwise, edgewise and flexural tests with different core densities and core thickness.

- It was found that compressive modulus in flatwise compression increased with increase in density by $64.20 \%$ while keeping the thickness constant. With change in thickness there was a marginal increase in compressive modulus by $19 \%$ while keeping the density constant.

- The ultimate load in case of flatwise compression also steadily increased with increase in core density by $67.37 \%$ and $6.7 \%$ with increase in core thickness

- The edgewise compressive stress also steadily increased with the increase in core density by $21.9 \%$ and with increase in core thickness by $8.5 \%$

- It was noticed that with increase in core thickness and with higher loading the sandwich failed in mode IV type. With lesser core density the core face de bonding resulted.

- In case of flexural tests, the face bending stress increased by $56.84 \%$ with increase in core density and the same trend was noticed in ultimate load. 


\section{Acknowledgements}

The authors would like to thank the management, principal and hod of their respective institutions for the support extended in carrying out this research work.

\section{References}

[1] S.C Sharma, M. Krishna, Buckling response of stitched polyurethane foam composite structures, Journal of reinforced Plastics and Composites 23, 2004, 1267-1277.

[2] M. Mohamed, S. Anandan, Z. Huo, V. Birman, J. Volz, K. Chandrashekhara, Manufacturing and characterization of polyurethane based sandwich composite structures, Journal of Composites Structures, 123, 2015, 169 - 179.

[3] Dai J, Hahn HT. Flexural behavior of sandwich beams fabricated by vacuumassisted resin transfer molding. Compos Struct 2003;61:247-53.

[4] Manalo AC, Aravinthan T, Karunasena W, Islam MM. Flexural behavior of structural fiber composite sandwich beams in flatwise and edgewise positions. Compos Struct 2010;92:984-95.
[5] Xiong J, Ma L, Wu L, Liu J, Vaziri A. Mechanical behavior and failure of composite pyramidal truss core sandwich columns. Compos B 2011;42:938-45.

[6] Carlsson L., Sendlein S., Merry S., Characterization of core/face shear fracture of composite sandwich beam, J. Comp. Mater., 25, 101-116 (1991).

[7] Asad Mirzapour, Mohammad Hossein Beheshty*, and Mehdi Vafayan, The Response of Sandwich Panels with Rigid Polyurethane Foam Cores under Flexural Loading, Iranian Polymer Journal 14 (12), 2005, 1082-1088.

[8] Vijay Kumar. Ma, Bhimasen Soragaon, Fabrication and Evaluation of Multilayered Polyurethane Foam Core Sandwich Panels for Static Flexural Stiffness, Procedia Engineering 97 ( 2014 ) $1227-1236$.

[9] Jongman K., Stephen R., Design of sandwich structures for concentrated loading, Comp Struc., 59, 365-373 (2001).

[10] Sourabha S Havaldar, Ramesh S Sharma, "Experimental investigation of dynamic characteristics of multilayer PU foam Sandwich panels", Journal of Minerals and Materials characterization and Engineering, 2013, 1, 201-206. 